\title{
Simposio Acta Médica Colombiana 40 Años
}

\section{Symposium Acta Médica Colombiana 40 Years}

\author{
Paulo Emilio Archila • Bogotá, D.C. (Colombia)
}

Con el presente suplemento pretendemos hacer una conmemoración del cuadragésimo aniversario de la revista, que complemente el contenido del simposio que se llevará a cabo en Montería, el día 15 de agosto en el marco del Congreso ACMI-ACP que se desarrolla en esa ciudad.

Hemos querido llegar a los lectores, autores y estudiantes con una edición que cumpla el objetivo educativo misión de nuestra actividad, haciendo conocer las intimidades de la gestión de una revista biomédica.

El material contenido en este suplemento deberá ser conservado como referencia, siempre que se quiera escribir un trabajo científico o darle lectura crítica.

Se publican las conferencias del simposio, en las cuales se conocerá nuestra historia, los elementos para la correcta presentación de trabajos, las normas de citación, los conflictos de interés, los requerimientos éticos y los problemas generados por la falsa citación y por el plagio, escritas por algunos miembros del Comité Editorial.

Se ilustran muchos conceptos con la reproducción de dos editoriales y dos conferencias Lombana Barreneche, así como un artículo original tomados de números anteriores de la revista, pertinentes a este suplemento educativo.

Finalmente se reproducen los Requisitos Uniformes actualizados en 2014 para la publicación de trabajos biomédicos y el documento sobre las Unidades de medida, por las cuales se rige nuestra publicación.

Este es un esfuerzo más para unificar nuestra comunidad médica, alrededor de su fuente de comunicación durante toda la vida de la Asociación Colombiana de Medicina Interna.

Dr. Paulo Emilio Archila

Editor Invitado 